\title{
LETTERS
}

\section{Weight loss with purpura and pain at the distal femora}

\section{K F Haegele, N J Buechner, C A Stueckle, L C Rump, S M Weiner}

Ann Rheum Dis 2005;64:1373-1374. doi: 10.1136/ard.2004.023325

$\mathrm{P}$ araneoplastic syndromes may occur as the first clinical symptom at an early stage of malignant diseases in about $7-10 \%$ of cases. ${ }^{1}$ As presented here, intensive investigations may be necessary to uncover an early curable tumour.

\section{CASE REPORT}

A 72 year old man presented with multiple purpuric and necrotising skin eruptions (sized 2-20 mm) covering mainly the extremities and, to a lesser extent, the trunk. He had noticed a weight loss of $12 \mathrm{~kg}$ in the past 2 months. There

was a history of smoking with chronic obstructive pulmonary disease and partial colectomy because of a benign adenoma. Laboratory investigations showed a normal erythrocyte sedimentation rate $(9 \mathrm{~mm} / \mathrm{lst} \mathrm{h})$, but $\mathrm{C}$ reactive protein was raised $(43 \mathrm{mg} / \mathrm{l})$. Serological markers, such as antinuclear antibodies, antineutrophil cytoplasmic antibodies, cryoglobulins, and hepatitis B and hepatitis C were excluded. A diagnostic procedure was performed to exclude a neoplasm, but, chest radiography, abdominal ultrasonography, gastroscopy, and colonoscopy were normal. Prednisone was
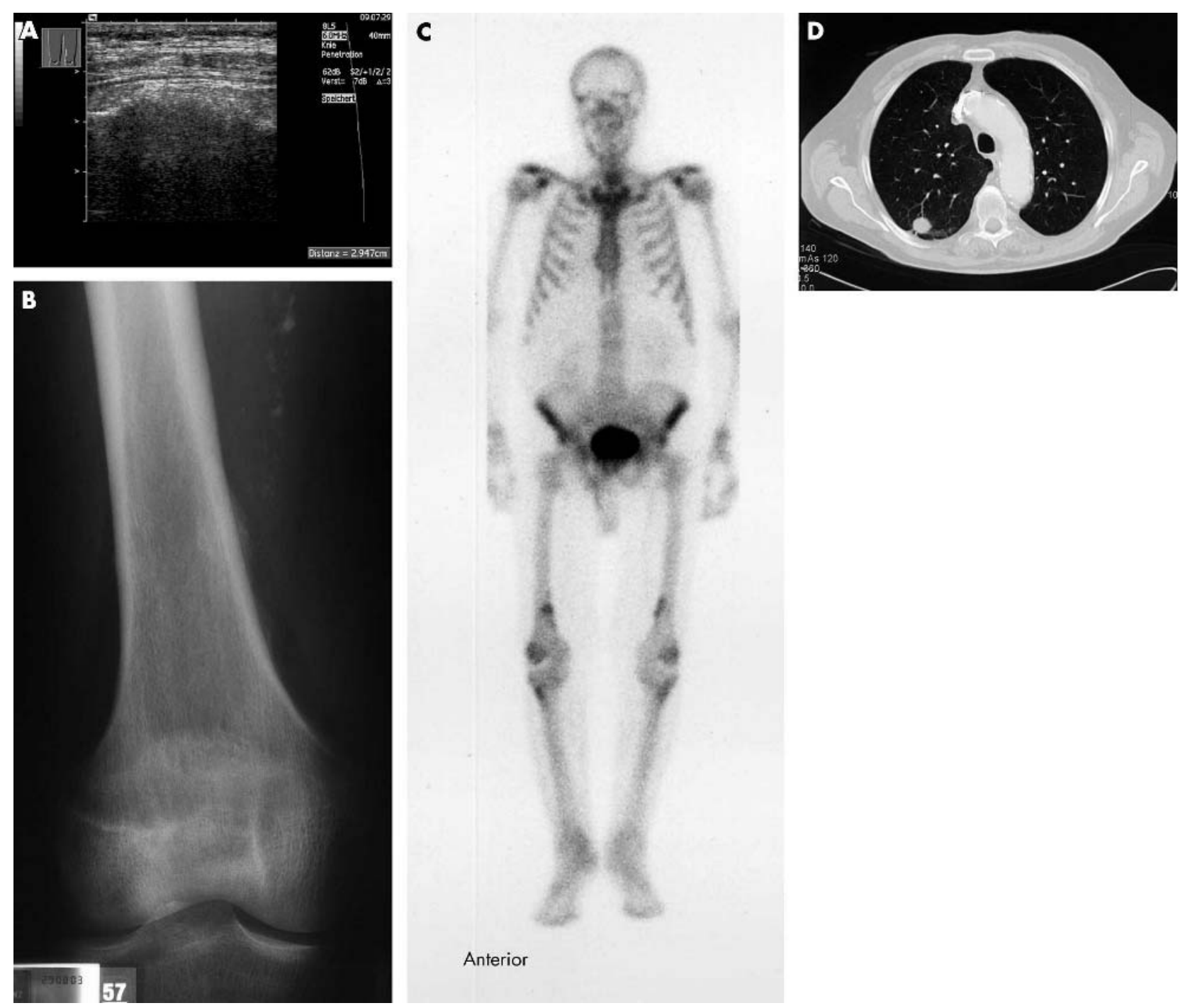

Figure 1 (A) Musculoskeletal ultrasound demonstrated an echogenic irregular focus above the surface of the distal femoral bone with distal acoustic shadowing (longitudinal scan). (B) Plain radiography of the right femur disclosed smooth, lamellated periosteal new bone formation, consistent with hypertrophic osteoarthropathy. (C) A bone scan showed irregular increased uptake involving the distal femur bilaterally. (D) Computed tomography of the chest showed a small mass at the right lung. 


\begin{tabular}{|c|c|}
\hline $\begin{array}{l}\text { Diseases associated with } \\
\text { periostitis }\end{array}$ & Predominant location of periostitis \\
\hline Hypertrophic osteoarthropathy & $\begin{array}{l}\text { Distal diaphysis of long bones and } \\
\text { metacarpal joints }\end{array}$ \\
\hline $\begin{array}{l}\text { Psoriatic onycho-pachydermo } \\
\text { periostitis }\end{array}$ & Terminal phalan $x$ \\
\hline $\begin{array}{l}\text { Psoriatic arthritis } \\
\text { Reiter's syndrome }\end{array}$ & $\begin{array}{l}\text { Phalanges of fingers and toes } \\
\text { Phalanges of fingers and toes }\end{array}$ \\
\hline $\begin{array}{l}\text { Athletic overuse (running, } \\
\text { jumping) }\end{array}$ & Upper and lower extremities \\
\hline Ossifying fasciitis & Variable \\
\hline Periostitis ossificans & Variable \\
\hline Polyarteritis nodosa & Lower extremities \\
\hline Systemic lupus erythematosus & Variable \\
\hline Facial infections & Mandibule, orbita \\
\hline Florid reactive periostitis & Phalanges of hands and feet \\
\hline Osteoblastoma & Variable \\
\hline $\begin{array}{l}\text { Bizarre parosteal } \\
\text { osteochondromatous proliferation } \\
\text { (Norg's tumour) }\end{array}$ & Bones of the hands and feet \\
\hline $\begin{array}{l}\text { (Nora's fumour) } \\
\text { Chondrosarcoma }\end{array}$ & Variable \\
\hline Treatment with interleukin 11 & Clavicle, long bones \\
\hline Osteomyelitis & Variable \\
\hline Chronic leg ulcers & Tibia \\
\hline SAPHO syndrome & Variable \\
\hline
\end{tabular}

given at a dose of $1 \mathrm{mg} / \mathrm{kg}$ body weight, with gradual improvement of the cutaneous vasculitis.

During the residential period the patient complained of pain in the region of the distal femur and the ankle bilaterally. Musculoskeletal ultrasound of the knee joints showed an effusion of $6 \mathrm{ml}$ from the right and $3 \mathrm{ml}$ from the left, without signs of synovitis, but discrete osteophytes. However, at the surface of the distal femoral bone echogenic irregular foci bilaterally with distal acoustic shadowing were seen, suggesting periosteal calcifications (fig 1A). An $x$ ray examination confirmed symmetric periosteal reactions of the femora of both sides (fig 1B), compatible with periostitis. Inflammatory activity was shown by a significant enhancement in both distal femora in a three phase bone scan with technetium-99m DPD (fig 1C).

Even though there was no sign of a tumour on the standard chest radiographs a computed tomographic scan of the lung was performed. A suspect lesion of $1.9 \mathrm{~cm}$ in diameter in the right lung was seen (fig 1D). A transthoracic puncture showed a highly differentiated adenocarcinoma of the lung. No metastasis was seen. The patient was referred to a thoracic surgeon and the tumour was excised. Reevaluation 6 months after excision of the tumour showed complete remission of bone pain and vasculitis without immunosuppressive treatment.

\section{DISCUSSION}

Our patient presented with two paraneoplastic syndromes: hypertrophic osteoarthropathy and cutaneous vasculitis.

Hypertrophic osteoarthropathy is most commonly seen in Pierre-Marie-Bamberger's syndrome. This syndrome is characterised by the concurrence of clubbed fingers, arthralgia, and painful periostitis of the extremities, and occurs in pulmonary, cardiac, hepatic, or intestinal diseases. ${ }^{2}$ Rarely, periostitis may be the only manifestation of Pierre-MarieBamberger's syndrome ${ }^{3}$ as in our patient. The periostitis is the result of subperiosteal bone formation, occurring mainly on the distal diaphysis of the long bones. Effusions into the large joints with little inflammatory cell exudation are a frequent finding. The diagnosis of periostitis is usually made by radiography and by bone scan. As we showed, musculoskeletal ultrasound may also visualise periostitis, but it is needed especially to look for periosteal lesions far from the adjacent joints. Table 1 presents other conditions associated with periostitis.

Non-small lung cell cancer is the most common malignancy associated with both Pierre-Marie-Bamberger's syndrome and cutaneous vasculitis. ${ }^{45}$ However, hypertrophic osteoarthropathy is more common (4.9\% in one study) than paraneoplastic vasculitis in patients with lung cancer. ${ }^{67}$ Differential diagnosis includes polyarteritis nodosa and systemic lupus erythematosus; both have been associated with periosteal reactions and vasculitis in anecdotal reports. ${ }^{8-10}$ However, as demonstrated by our case, computed tomography of the lung should be performed in the presence of unexplained vasculitis or periostitis, or both, even if standard chest radiography of the lung shows no pathological findings.

\section{Authors' affiliations}

K F Haegele, N J Buechner, L C Rump, S M Weiner, Medizinische Klinik I, Marienhospital, Klinikum der Ruhr-Universität Bochum, Herne, Germany

C A Stueckle, Radiologie, Marienhospital, Klinikum der Ruhr-Universität Bochum, Herne, Germany

Correspondence to: Dr S M Weiner, Medizinische Klinik I, Marienhospital, Klinikum der Ruhr-Universität Bochum, Hölkeskampring 40, 44625 Herne, Germany; stefan.weiner@ruhr-uni-bochum.de

Accepted 7 February 2005

\section{REFERENCES}

1 Abu-Shakra M, Buskila D, Ehrenfeld M, Conrad K, Shoenfeld Y. Cancer and autoimmunity: autoimmune and rheumatic features in patients with malignancies. Ann Rheum Dis 2001;60:433-40.

2 Martinez-Lavin M. Hypertrophic osteoarthropathy. Curr Opin Rheumatol 1997;9:83-6.

3 Clarke S, Barnsley L, Peters M, Morgan L, Van der Wall H. Hypertrophic pulmonary osteoarthropathy without clubbing of the digits. Skeletal Radiol 2001;30:652-5.

4 Pankow W, Neumann K, von Wichert P. Bronchial carcinoma associated with pulmonary osteoarthopathy (Marie-Bamberger disease). Pneumologie 1990;44:1306-11.

5 Kurzrock R, Cohen PR, Markowitz A. Clinical manifestations of vasculitis in patients with solid tumors. A case report and review of the literature. Arch Intern Med 1994; 14:334-40.

6 Suteanu S, Rohan C, Gherasim E, Stoica V. Hypertrophic osteoarthropathy secondary to bronchopulmonary cancer (our experience). Rom J Intern Med 1992;30:281-4.

7 Greer JM, Longley S, Edwards L, Elfenbein GJ, Panush RS. Vasculitis associated with malignancy. Experience with 13 patients and literature review of literature. Medicine (Baltimore) 1988;67:220-30.

8 Astudillo LM, Rigal F, Couret B, Arlet-Suau E. Localized polyarteritis nodosa with periostitis. J Rheumatol $2001 ; 28: 2758-9$.

9 Aries PM, Reuter M, Lamprecht P, Gross WL. Periostitis as the initial manifestation of systemic vasculitis. Ann Rheum Dis 2005:64:329-30.

10 Glickstein M, Neustadter L, Dalinka M, Kricun M. Periosteal reaction in systemic lupus erythematosus. Skeletal Radiol 1986;15:610-12. 


\title{
Long term infliximab treatment for severe psoriatic arthritis: evidence of sustained clinical and radiographic response
}

\author{
F Rinaldi, G Provenzano, A Termini, M Spinello, F La Seta
}

Ann Rheum Dis 2005;64:1375-1376. doi: 10.1136/ard.2004.033233

$\mathrm{P}$

soriatic arthritis (PsA) affects about $30 \%$ of patients with psoriasis and is a chronic inflammatory rheumatic disease, with the development of erosive and deforming arthritis in about $40 \%$ of patients. ${ }^{1}$ Tumour necrosis factor $\alpha$ $(\mathrm{TNF} \alpha)$ has an established role in the pathogenesis of PsA, and the TNF $\alpha$ receptor blocker etanercept has been approved for its treatment. ${ }^{2}$

There are also encouraging data about the efficacy of infliximab, ${ }^{3-5}$ but its long term efficacy and safety in PsA have been questioned. ${ }^{6}$

\section{METHODS AND RESULTS}

We evaluated in an open label, 2 year study the safety and efficacy of infliximab in association with methotrexate for patients with severe PsA. This study was an extension protocol of an initial 6 month study.

Four men and eight women with PsA and active disease despite treatment with methotrexate + steroid + nonsteroidal anti-inflammatory drugs had been enrolled and treated with five infusions of infliximab (Remicade, Centocor) at a dose of $5 \mathrm{mg} / \mathrm{kg}$ at weeks $0,2,6,14$, and 22 . Thereafter the patients continued treatment with $5 \mathrm{mg} / \mathrm{kg}$ every 6 or 8 weeks for up to 2 years.

The patients had a mean (SD) age of 48.4 (13.6) years and a mean duration of articular symptoms of 8.6 (5.6) years. Eleven of the 12 patients had a polyarticular pattern of disease with predominantly peripheral arthritis. Two patients had been withdrawn from the study before the fifth infusion owing to the occurrence of severe diseases and another patient had to stop infliximab after the seventh infusion owing to a lymphadenitis due to cytomegalovirus. Nine patients continued infliximab treatment for up to 2 years.

The following outcome measures were evaluated: patient evaluation of global health status ( $100 \mathrm{~mm}$ visual analogue scale (VAS)); patient global assessment of disease activity (100 mm VAS); patient assessment of pain (100 mm VAS); Health Assessment Questionnaire (HAQ) scores; physician global assessment of disease activity (100 mm VAS); tender joint count; swollen joint count; erythrocyte sedimentation rate
(ESR); C reactive protein level (CRP); Psoriasis Area and Severity Index (PASI).

The American College of Rheumatology (ACR) improvement criteria for rheumatoid arthritis with $20 \%$, 50\%, and $70 \%$ improvement were also assessed.

Radiographs of the hands and wrists were obtained at baseline and at 2 years for the patients with peripheral polyarthritis completing 2 years of infliximab treatment and were scored according to the modified Sharp's method. ${ }^{8}$

At week 26 a significant decrease $(p \leqslant 0.05$, by $t$ test for paired data) had been seen for all variables, with the exception of ESR. At 1 and 2 years a significant decrease was maintained for all the outcome measures, with the persisting exception of ESR (table 1). Seven patients had received infliximab every 8 weeks, two of them every 6 weeks owing to a partial loss of efficacy.

At 1 year, 8/9 (89\%) patients met the ACR20 and 6/9 (67\%) patients the ACR70. At 2 years $9 / 9$ (100\%) patients met the ACR20 and 5/9 (56\%) patients the ACR70.

Eight of nine patients completing 2 years of infliximab treatment had a predominantly peripheral polyarthritis. In these eight patients we did not observe a significant increase of radiographic Sharp's score from baseline (table 2). In 5/8 $(63 \%)$ patients we did not see any increase in Sharp's score at the end of 2 years of infliximab treatment.

\section{DISCUSSION}

Our data suggest that long term treatment with infliximab may be highly effective for patients with severe PsA. These results are in partial contrast with those from another observational study, ${ }^{6}$ but similar to other recent observations. ${ }^{9}$ TNF $\alpha$ neutralising agents are being used by an increasing number of patients with PsA and the Italian Society of Rheumatology has recently published specific guidelines for their appropriate use. ${ }^{10}$

PsA is a heterogeneous disease and we need larger studies and more data to better select patients with PsA who may benefit from anti-TNF $\alpha$ treatment.

Table 1 Outcome measures at baseline, week 26, years 1 and 2. Values are given as mean (SD)

\begin{tabular}{lllll}
\hline Outcome measure & $\begin{array}{l}\text { Baseline } \\
\text { (12 patients) }\end{array}$ & $\begin{array}{l}\text { Week 26 } \\
\text { (10 patients) }\end{array}$ & $\begin{array}{l}\text { Year 1 } \\
\text { (9 patients) }\end{array}$ & $\begin{array}{l}\text { Year 2 } \\
\text { (9 patients) }\end{array}$ \\
\hline Patient health status & $28.3(22.1)$ & $63.0(23.6)^{*}$ & $77.2(10.9)^{*}$ & $77.8(13.9)^{*}$ \\
Patient pain & $84.2(17.3)$ & $33.0(27.1)^{*}$ & $33.3(29.6)^{*}$ & $26.7(20.6)^{*}$ \\
Patient disease activity & $82.5(18.6)$ & $28.0(16.2)^{*}$ & $27.8(27.7)^{*}$ & $25.5(16.7)^{*}$ \\
HAQ score & $2.0(0.6)$ & $0.9(1.1)^{*}$ & $0.6(0.6)^{*}$ & $0.6(0.8)^{*}$ \\
Physician disease activity & $74.2(14.4)$ & $27.0(17.0)^{*}$ & $22.2(19.9)^{*}$ & $23.3(15)^{*}$ \\
Tender joint count & $31.7(22.9)$ & $9.6(12.7)^{*}$ & $10.1(12.0)^{*}$ & $3.7(4.4)^{*}$ \\
Swollen joint count & $9.9(6.8)$ & $2.3(4.6)^{*}$ & $1.9(4.3)^{*}$ & $0.5(1.1)^{*}$ \\
PASI & $12.1(10.3)$ & $1.1(2.7)^{*}$ & $2.2(4.5)^{*}$ & $0.4(0.4)^{*}$ \\
ESR (mm/1st h) & $21.6(15.5)$ & $20.2(20.4)$ & $14.3(10.8)$ & $21.1(16.9)$ \\
CRP (mg/l) & $0.9(0.9)$ & $0.2(0.4)^{*}$ & $0.2(0.5)^{*}$ & $0.3(0.5)^{*}$ \\
\hline
\end{tabular}

${ }^{*} p \leqslant 0.05$ as compared with baseline (determined by $t$ test for paired data). 
Table 2 Evaluation of radiographic progression of joint damage according to modified Sharp's score leight patients)

\begin{tabular}{lll}
\hline & Baseline & $\begin{array}{l}\text { After 2 years of } \\
\text { infliximab }\end{array}$ \\
\hline Global Sharp's score & $65.4(43.5)$ & $66(43.2)$ \\
Erosions & $33.9(24.2)$ & $34.5(23.9)$ \\
Joint space narrowing & $31.5(19.9)$ & $31.5(19.9)$ \\
\hline
\end{tabular}

$p$ non-significant as determined by $t$ test for paired data.

Values are given as mean (SD).

\section{Authors' affiliations \\ F Rinaldi, A Termini, M Spinello, Division of Internal Medicine II, AO "V. Cervello", Palermo, Italy \\ G Provenzano, Department of Medicine, Division of Respiratory Diseases, Section of Systemic Autoimmune Diseases, AO "Villa Sofia- CTO", Palermo, Italy \\ F La Seta, Service of Radiology, AO "V. Cervello"; Palermo, Italy}

Correspondence to: Dr G Provenzano, Department of Medicine, Division of Respiratory Diseases, Section of Systemic Autoimmune Diseases, Azienda Ospedaliera "Villa Sofia-CTO", Via Ingegneros No 33, 90100 Palermo, Italy; giuseppe.provenzano5@tin.it

\section{REFERENCES}

1 Gladman DD. Psoriatic arthritis. Rheum Dis Clin North Am 1998;24:829-44.

2 Mease PJ, Kivitz AJ, Burch FX, Siegel EL, Cohen SB, Ory P, et al. Etanercept treatment of psoriatic arthritis. Safety, efficacy and effect on disease progression. Arthritis Rheum 2004;50:2264-72.

3 Van den Bosch F, Kruithof E, Baeten D, Herssens A, de Keyser F, Mielans H, et al. Randomized double-blind comparison of chimeric monoclonal antibody to tumour necrosis factor- $\alpha$ infliximab versus placebo in active spondyloarthropathy. Arthritis Rheum, 2002;46:755-65.

4 Antoni C, Dechant C, Hanns-Martin Lorenz PD, Wendler J, Ogilvie A, Lueftl M, et al. Open label study of infliximab treatment for psoriatic arthritis: clinical and magnetic resonance imaging measurements of reduction of inflammation. Arthritis Rheum 2002;47:506-12.

5 Salvarani C, Cantini F, Olivieri I, Macchioni P, Padula A, Niccoli L, et al. Efficacy of infliximab in resistant psoriatic arthritis. Arthitis Rheum 2003:49:541-5

6 Feletar M, Brockbank JE, Schentag CT, Lapp V, Gladman DD. Treatment of refractory psoriatic arthritis with infliximab: a 12 month observational study of 16 patients. Ann Rheum Dis 2004;63:156-61.

7 Provenzano G, Termini A, Le Moli C, Rinaldi F. Efficacy of infliximab in psoriatic arthritis resistant to therapy with disease modifying antirheumatic drugs: an open pilot study. Ann Rheum Dis 2003;62:680-1.

8 Sharp JT, Ypung DY, Bluhm JB, Brook A, Brower AC, Corbett M, et al. How many joints in the hands and wrists should be included in a score of radiologic abnormalities used to assess rheumatoid arthritis ? Arthritis Rheum 1985;28:1326-35.

9 Yazdani-Biuki B, Wohlfart K, Mulabecirovic A, Mueller T, Hermann J, Graninger WB, et al. Long term treatment of psoriatic arthritis with infliximab. Ann Rheum Dis 2004:63:1531-2.

10 Salvarani C, Olivieri I, Cantini F, Marchesoni A, Punzi L, Scarpa R, et al. Reccomendations for the appropriate use of anti-TNF $\alpha$ therapy in patients with psoriatic arthritis. Reumatismo 2004;56:133-8.

\section{Topical tacrolimus treatment in a patient with dermatomyositis}

\section{E Lampropoulos, D P D' Cruz}

D ermatomyositis is an idiopathic inflammatory process manifested by proximal muscle weakness and cutaneous lesions such as Gottron's sign, heliotrope rash, erythematous photosensitive rash, or periungual erythema. Other unusual cutaneous manifestations are icthyosis, panniculitis, erythroderma, lichen planus, vesicle and bullae formation, follicular hyperkeratosis, malacoplakia, and papular mucinosis. ${ }^{1}$ Administration of systemic agents such as corticosteroids, methotrexate (MTX), hydroxychloroquine (HCQ), mycophenolate mofetil, intravenous immunoglobulins, and/or azathioprine for the underlying systemic disease leads in many cases to remission of the cutaneous lesions. Nevertheless, many patients have resistant cutaneous lesions despite treatment. On the other hand, cutaneous lesions may be the major manifestation of the disease, making it difficult to justify systemic agents because of their side effects.

\section{CASE REPORT}

A 61 year old woman with dermatomyositis and cutaneous lesions, refractory to previous treatment, with good response to tacrolimus ointment is described. Her cutaneous lesions comprised a photosensitive rash over her face, neck and hands, heliotrope rash, and Gottron's sign.

Treatment was started with MTX (10 mg/week intramuscularly). Two months later, the muscle weakness was markedly improved, but the cutaneous lesions were still active with accompanying pain and pruritus. MTX was increased to $15 \mathrm{mg} /$ week and HCQ was added (200 mg/day with gradual increase to $400 \mathrm{mg} /$ day), but after 1 year there was no response and HCQ was discontinued. The extensive cutaneous lesions were temporarily relieved with oral prednisolone. The photosensitive rash worsened after exposure to fluorescent lamps, and monochromator light testing showed a marked papular reaction and sensitivity to the emissions of the lamps. In 2002, MTX was discontinued as it had had no efficacy on the skin lesions.

One year later she had a severe flare of her skin disease over the face, arms, and upper chest without any proximal weakness. Tacrolimus ointment $0.1 \%$ was suggested as an alternative treatment and with her informed consent she started applying it twice a day over the affected areas. Four weeks later there was a good response of the skin rashes, especially of the upper chest (fig 1). Tacrolimus ointment was discontinued, but after 1 month the patient had another flare of the skin rash. Tacrolimus ointment was restarted and the lesions improved. To date, her cutaneous lesions remain in remission with continuous use of the ointment.

\section{DISCUSSION}

Tacrolimus-isolated in 1984 from the fungus Streptomyces tsukubaensis-is a macrolide immunomodulator FK506, which acts on T lymphocytes and inhibits interleukin 2 transcription as well as other cytokines. ${ }^{2}$ Since 1989 it has been widely used in preventing graft rejection after transplantation (liver, kidneys, lungs). ${ }^{3}$ In $2000^{4}$ tacrolimus ointment was approved for the treatment of atopic dermatitis. ${ }^{5}$ Efficacy is similar or even better than corticosteroids (especially in children or for facial lesions, where only weak steroids can be used), without 

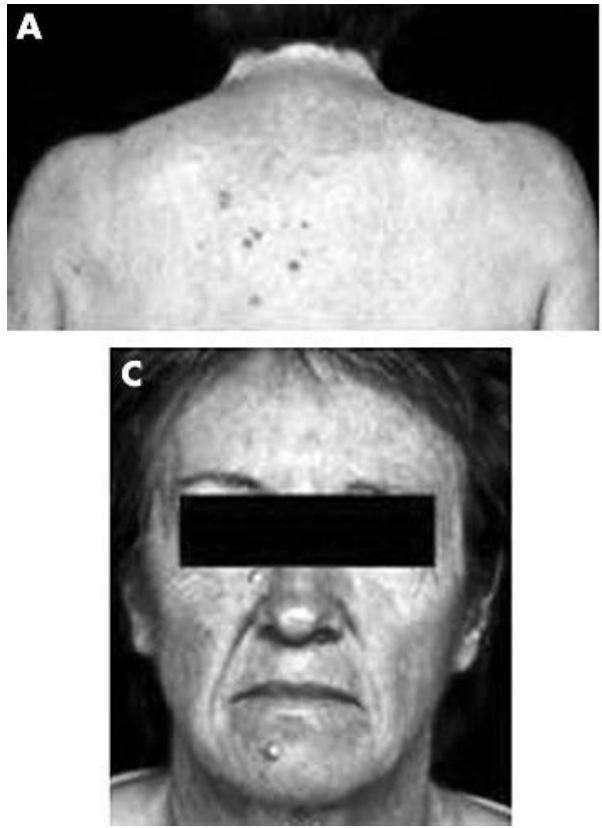
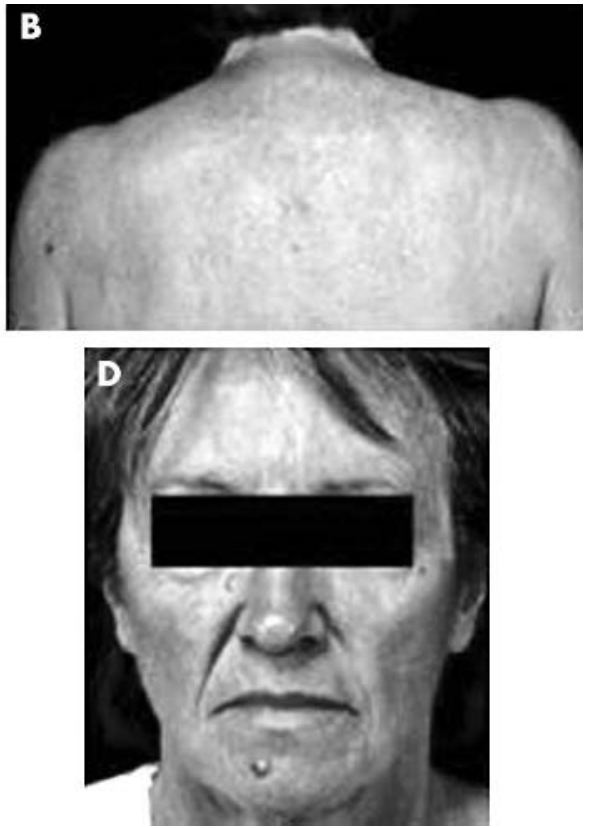

Figure 1 ( $A, C)$ Photosensitive rash on face and back upper chest before treatment. (B, D) Improvement of the cutaneous lesions 4 weks later. A colour version of the figure can be seen at http://www.annrheumdis.com/ supplemental. Reproduced with the patient's permission. the adverse effects of skin atrophy (no impairment of collagen synthesis) and serious systemic absorption. ${ }^{6}$ Common side effects are burning sensations, itching, or erythema, which usually decline as treatment is continued owing to improvement of the skin's condition. ${ }^{7}$ Tacrolimus also seems to be effective in resistant cutaneous lesions of other diseases such as psoriasis, localised scleroderma, chronic actinic dermatitis, pyoderma gangrenosum, Behçet's disease, lichen planus, rheumatoid ulcers, and steroid rosacea.

To date, there are a few case reports and a pilot study suggesting good therapeutic efficacy of tacrolimus ointment in connective tissue diseases like dermatomyositis. ${ }^{8-10}$ Our patient's cutaneous lesions, which had been refractory to any previous treatment, seemed to respond well. These results suggest that tacrolimus ointment could be considered as an alternative treatment for resistant cutaneous lesions in dermatomyositis.

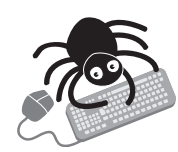

\section{A colour version of fig 1 can be found at http://} www.annrheumdis.com/supplemental

\section{Authors' affiliations}

C E Lampropoulos, D P D' Cruz, Lupus Research Unit, The Rayne Institute, St Thomas' Hospital, London, UK

Competing interest statement: Neither of the authors have any competing interests.
Correspondence to: DrD P D' Cruz, The Lupus Research Unit, The Rayne Institute, St Thomas' Hospital, 4, Lambeth Palace Road, London SEl 7EH, UK; david.d'cruz@kcl.ac.uk

Accepted 14 January 2005

\section{REFERENCES}

1 Kovacs SO, Kovacs SC. Dermatomyositis. J Am Acad Dermatol 1998;39:899-920.

2 Sawada S, Suzuki G, Kawase Y, Takaku F. Novel immunosuppressive agent, FK506. In vitro effects on the cloned T cell activation. J Immunol 1987;139:1797-803.

3 Starzl TE, Todo S, Fung J. FK506 for liver, kidney and pancreas transplantation. Lancet 1989;8670:1000-4.

4 US FDA. US FDA Advisory Committee recommends approval for tacrolimus ointment. Skin Therapy Letter 2000;6:5.

5 Kang S, Lucky AW, Pariser D, Lawrence I, Hanifin JM. Long-term safety and efficacy of tacrolimus ointment for the treatment of atopic dermatitis in children. J Am Acad Dermatol 2001;44(suppl 1):S58-64.

6 Bos JD. Non-steroidal topical immunomodulators provide skin-selective and self-limiting treatment in atopic dermatitis. Eur J Dermatol 2003; 13:455-61.

7 Soter NA, Fleischer AB, Webster OF. Tacrolimus ointment fort the treatment of atopic dermatitis in adult patients: part II, safety. J Am Acad Dermatol, 2001;44(suppl 1):S39-46.

8 Lampropoulos CE, Sangle S, Harrison P, Hughes GRV, D' Cruz DP. Topical tacrolimus therapy of resistant cutaneous lesions in lupus erythematosus: a possible alternative. Rheumatology (Oxford) 2004;20:54-7.

9 Hollar CB, Jorizzo JL. Topical tacrolimus 0 . 1\% ointment for refractory skin disease in dermatomyositis: a pilot study, J Dermatolog Treat 2004; 15:35-9.

10 Yoshimasu T, Ohtani T, Sakamoto T, Oshima A, Furukawa F. Topical FK506 (tacrolimus) therapy for facial erythematous lesions of cutaneous lupus erythematosus and dermatomyositis. Eur J Dermatol 2002;12:50-2. 


\title{
Surgery in patients receiving anti-tumour necrosis factor $\alpha$ treatment in rheumatoid arthritis: an observational study on 50 surgical procedures
}

\author{
D Wendling, J-C Balblanc, A Brousse, A Lohse, G Lehuede, P Garbuio, E Toussirot, B Auge, \\ D Jacques
}

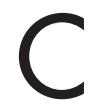
urrently, little information is available about the interaction between anti-tumour necrosis factor (TNF) treatment and surgery. ${ }^{1}$

In an attempt to evaluate the relative safety of anti-TNF and its impact on the course of disease in patients with rheumatoid arthritis (RA) undergoing surgery, we included in a retrospective study all such patients followed up in a regional network. The network allows close follow up as the patients regularly renew their prescription at the hospital. Surgical outcomes focused on infection and other complications together with the postoperative impact on RA disease activity. A flare of RA was defined as an increase in the joint count and global assessment of $>20 \%$.

Fifty surgical procedures were recorded in 30 patients with RA ( 25 women), with a mean age of 54.6 years, a mean disease duration of 12.3 years, and a mean of 3.7 previous disease modifying antirheumatic drugs. In 38 cases, anti-TNF was associated with a disease modifying antirheumatic drug (methotrexate 33 cases) and with general steroid treatment in $41 / 50$ patients receiving a mean of $8.2 \mathrm{mg} / \mathrm{day}$ of prednisone. The TNF blocker at the time of surgery was infliximab $(n=26)$, etanercept $(n=13)$, adalimumab $(\mathrm{n}=11)$, with a mean exposure to an anti-TNF agent of 12.1 months (range 1-42). Discontinuation of the anti-TNF agent occurred before surgery in 18/50 patients, and for the rest, surgery was performed between two anti-TNF injections.

Table 1 summarises the type of surgery; the mean follow up after surgery was 14 months (range 1-42). No major complications, especially infections, occurred in either group whether the anti-TNF agent was disontinued or not. Three cases $(6 \%)$ of minor postoperative side effects were recorded (delay of wound healing of $1-2$ weeks). Six cases (12\%) of moderate short lasting RA flares were reported occurring with each TNF blocker, in orthopaedic surgery, and significantly associated with anti-TNF interruption before surgery ( 5 interruptions/6 cases of flare versus 13 interruptions/44 surgical procedures without flare; Fisher's exact $p$ value $=0.02$ )

In this group of patients with classic RA receiving an antiTNF agent, the main result was the absence of a major complication after surgery, particularly pyogenic infection. ${ }^{23}$ Methotrexate does not seem to have deleterious impact upon surgical outcome in RA. ${ }^{4}$

In Crohn's disease, Marchal et al found no significant differences in postoperative early minor or major complications or in duration of hospitalisation between infliximab exposed and infliximab naïve patients. ${ }^{5}$ In RA, Bibbo and Goldberg found similar rates of complications in both groups (16 patients receiving an anti-TNF agent compared with 15 matched anti-TNF naïve patients) in foot and ankle surgery. ${ }^{\circ}$

In our study the overall rate of complication is lower than reported in large studies of anti-TNF $\alpha$ treatment, irrespective

\begin{tabular}{|lc|}
\hline $\begin{array}{l}\text { Table } 1 \text { Type of surgery in patients } \\
\text { receiving an anti-TNF agent }\end{array}$ \\
\hline & No of \\
patients \\
\hline Type of surgery & 39 \\
\hline Orthopaedic & 13 \\
Foot and ankle & 11 \\
Hand and wrist & 12 \\
Total joint replacement & 4 \\
Hip & 3 \\
Shoulder & 2 \\
Knee & 1 \\
Elbow & 2 \\
Finger & 3 \\
Miscellaneous & 11 \\
Non-orthopaedic & 5 \\
Head and neck & 6 \\
Abdomen & \\
\hline
\end{tabular}

of surgery. For example the percentage of patients developing severe infection is $2 \%$ in the ATTRACT study ${ }^{7}$ (infliximab in RA), $4 \%$ in the ACCENT study in Crohn's disease, ${ }^{8}$ and up to $18 \%$ in some RA cohort studies. ${ }^{9}$ The retrospective design, the size of our population, the absence of comorbidities and of a control group may represent bias in the present study. Recently, Giles et al reported an increased risk of infection (odds ratio $=5.3$ ) during orthopaedic surgery for patients receiving an anti-TNF agent. ${ }^{10}$

Our observational study did not find an increased frequency of adverse events related to uninterrupted use of anti-TNF treatment in patients with RA undergoing surgery.

\section{Authors' affiliations}

D Wendling, J-C Balblanc, A Brousse, A Lohse, G Lehuede, P Garbuio, E Toussirot, B Auge, D Jacques, Regional Rheumatologic Network for Biotherapies, Department of Rheumatology, University Teaching Hospital, F-25030 Besançon, France

Correspondence to: Professor D Wendling, daniel.wendling@ ufc-chu.univ-fcomte. fr

Accepted 6 March 2005

\section{REFERENCES}

1 Jain A, Maini R, Nanchahal J. Disease modifying treatment and elective surgery in rheumatoid arthritis: the need for more data. Ann Rheum Dis 2004;63:602-3

2 Ellerin T, Rubin RH, Weinblatt ME. Infections and anti-tumor necrosis factor alpha therapy. Arthritis Rheum 2003:48:3013-22.

3 Rosandich PA, Kelley JT, Conn DL. Perioperative management of patients with rheumatoid arthritis in the era of biologic response modifiers. Curr Opin Rheumatol 2004;16:192-8. 
4 Sany J, Anaya JM, Canovas F, Combe B, Jorgensen C, Saker S, et al. Influence of methotrexate on the frequency of postoperative infectious complications in patients with rheumatoid arthritis. J Rheumatol 1993;20:1129-32.

5 Marchal L, D'Haens G, Van Assche G, Vermeire S, Noman M, Ferrante M, et al. The risk of post-operative complications associated with infliximab therapy for Crohn's disease: a controlled cohort study. Aliment Pharmacol Ther 2004; 19:749-54

6 Bibbo C, Goldberg JW. Infectious and healing complications after elective orthopaedic foot and ankle surgery during tumor necrosis factor-alpha inhibition therapy. Foot Ankle Int 2004;25:331-5.

7 Lipsky PE, Van der Heijde DM, St Clair EW, Furst DE, Breedveld FC, Kalden JR, et al. Infliximab and methotrexate in the treatment of rheumatoid arthritis.
Anti-tumor necrosis factor trial in rheumatoid arthritis with concomitant study group. N Engl J Med 2000;343:1594-602.

8 Hanaver SB, Feagan BG, Lichtenstein GR, Mayer LF, Schreiber S, Colombel JF, et al. Maintenance infliximab for Crohn's disease: the ACCENT I randomised trial. Lancet 2002;359:1541-9.

9 Kroesen S, Widmer AF, Tyndall A, Hasler P. Serious bacterial infections in patients with rheumatoid arthritis under anti-TNF-alpha therapy. Rheumatology (Oxford) 2003;42:617-21.

10 Giles JT, Gelber AC, Nanda S, Bartlett SJ, Bathon JM. TNF inhibitor therapy increases the risk of post operative orthopaedic infection in patients with rheumatoid arthritis [abstract]. Arthritis Rheum 2004;50(suppl):S660.

\section{Increase in methotrexate dose in patients with rheumatoid arthritis who have an inadequate response to infliximab}

\section{P Ornetti, E Solau, P Gaudin, J Sibilia, J-M Berthelot, X Puechal, C Tavernier, J F Maillefert, on behalf of the "Club Rhumatismes et Inflammation", from the French Society of Rheumatology}

T he strategy needed for patients with inadequate response to treatment with infliximab and methotrexate (MTX) is not well defined. It has been suggested that an increase in the infliximab dosage, a shortening of the intervals between infusions, or a switch to another anti-tumour necrosis factor $\alpha$ agent might provide clinical benefit. ${ }^{1-4}$ Another, less expensive, strategy might be to increase the MTX weekly dose in patients not co-treated with MTX at the maximal dose. This study aimed at evaluating the efficacy of increasing the MTX dose in patients with rheumatoid arthritis (RA) with active disease despite treatment with infliximab and MTX.

\section{METHODS AND RESULTS}

Data were obtained from six rheumatology departments that measure the 28 joint count Disease Activity Score (DAS28) before each infliximab infusion. All patients with RA with active disease (DAS28 $\geqslant 3.2$ ), despite treatment with a stable regimen of infliximab $(3 \mathrm{mg} / \mathrm{kg}$ at $0,2,6$ weeks, thereafter every 8 weeks) and MTX, in whom the MTX weekly dose was increased in order to obtain a better disease control, were included. The exclusion criteria were a change in corticosteroid daily dose or in infliximab regimen at the time of the change of MTX dose, or during the 16 weeks following. The DAS28 scores obtained at the first and second infusion after the change in MTX dose were compared with those obtained before the change (Wilcoxon paired test), and the percentages of responders (EULAR criteria) at the first and second infliximab infusion after the adjustment in MTX dosage were obtained.

A total of 22 patients with RA were included ( 15 female and 7 male, mean (SD) age 47 (9.1) years, mean (SD) disease duration 7.3 (3.9) years). At the time of adjustment of MTX dosage, patients had been treated with MTX and infliximab for a mean (SD) of $7.6(6.4)$ months. The mean (SD) MTX weekly dose was increased from 9.9 (3.9) $\mathrm{mg}$ to a mean of 15 (4.3) mg because of primary $(n=8)$, or secondary infliximab treatment failure $(n=7)$ or because the response was judged to be insufficient $(n=7)$. The change was tolerated well in all patients. The DAS28 scores decreased significantly after the MTX dose adjustment (table 1). Five (23\%) patients were considered as responders at 8 weeks (four moderate and one good response) and eight (36\%) at 16 weeks (seven moderate and one good response) (fig 1). However, according to the EULAR criteria, 21 (95\%) of the patients presented with active disease (DAS28 $\geqslant 3.2$ ) 16 weeks after the adjustment, and a disease remission (DAS28 $\leqslant 2.6$ ) was never observed.

\section{DISCUSSION}

These results might be regarded as disappointing: the mean disease activity showed only modest improvements, and the disease remained active in most patients. However, a response was observed in more than a third of the patients, a percentage which cannot be considered as anecdotal. This study was an observational cohort study, so it cannot be claimed that an increase in MTX dose is useful in patients with active disease despite infliximab treatment, because two main hypotheses can be put forward for explanation: (a) the increase in the MTX dose induces a clinical response in a relevant number of patients; $(b)$ the observed results are due to a regression to the mean effect; adjustment in the MTX dose is likely to be proposed when disease activity increases, so the observed improvement in disease activity might have occurred without a change in the MTX dose. Such a hypothesis was recently proposed to explain the improvement observed after infliximab dose escalation. ${ }^{5}$

Table 1 Disease activity before, and at the first ( 8 weeks) and second ( 16 weeks) infliximab infusion after MTX dose adjustment

\begin{tabular}{|c|c|c|c|}
\hline & \multirow[b]{2}{*}{$\begin{array}{l}\text { Before } \\
\text { adjustment }\end{array}$} & \multicolumn{2}{|c|}{ After adjustment } \\
\hline & & $\begin{array}{l}\text { First } \\
\text { infliximab } \\
\text { infusion }\end{array}$ & $\begin{array}{l}\text { Second } \\
\text { infliximab } \\
\text { infusion }\end{array}$ \\
\hline MTX dose (mg/weekly) & $9.9(3.9)$ & $15(4.3)$ & $15(4.3)$ \\
\hline DAS28 & $5.2(0.8)$ & $4.7(1.1)^{*}$ & $4.5(0.9)^{\star *}$ \\
\hline Tender joint count (/28) & $10.2(7)$ & $7.7(7)^{*}$ & $7.4(7)^{*}$ \\
\hline Swollen joint count $(/ 28)$ & $5.2(4)$ & $4.8(4)$ & 3.7 (4) \\
\hline ESR $(\mathrm{mm} / 1 \mathrm{st} h)$ & $32.1(21)$ & $28.9(17)$ & $27.2(17)$ \\
\hline $\begin{array}{l}\text { Patient global assessment } \\
(/ 100)\end{array}$ & $52.2(17)$ & $44(23)$ & $42(18)^{*}$ \\
\hline \multicolumn{4}{|c|}{$\begin{array}{l}\text { Results are shown as mean (SD). } \\
{ }^{*} p<0.05 ;{ }^{* *} p<0.01\end{array}$} \\
\hline
\end{tabular}




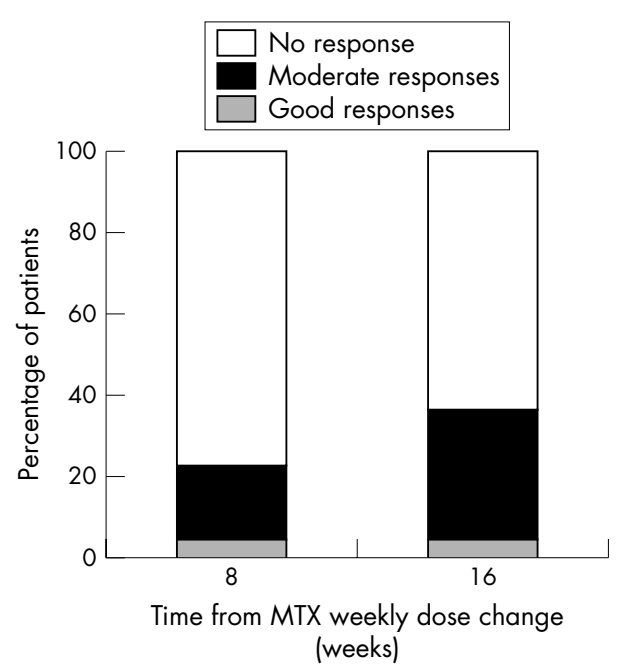

Figure 1 percentage of patients with good and moderate response (EULAR criteria) 8 and 16 weeks after an increase in the MTX weekly dose.

Further prospective studies are needed to determine the precise strategy to be used in patients with active RA despite infliximab treatment. While waiting for these, an increase in the MTX dose might be an inexpensive but well tolerated strategy which might be used as a first therapeutic option, or in combination with other changes in treatment for patients not treated with MTX at a maximal dose.

\begin{abstract}
Authors' affiliations
P Ornetti, C Tavernier, J F Maillefert, Department of Rheumatology, Dijon University Hospital, Dijon, France

E Solau, Department of Rheumatology, Lille University Hospital, Lille, France

P Gaudin, Department of Rheumatology, Grenoble University Hospital, Grenoble, France

J Sibilia, Department of Rheumatology, Strasbourg University Hospital, Strasbourg, France

J-M Berthelot, Department of Rheumatology, Nantes University Hospital, Nantes, France

X Puechal, Department of Rheumatology, le Mans Hospital, le Mans, France
\end{abstract}

Correspondence to: Dr J F Maillefert, Department of Rheumatology, Hôpital Général, 3 rue du Faubourg Raines, 21000 Dijon, France; jean-francis.maillefert@chu-dijon.fr

Accepted 2 January 2005

\section{REFERENCES}

1 Sidiropoulos P, Bertsias G, Kritikos HD, Kouroumali H, Voudouris K, Boumpas DT. Infliximab treatment for rheumatoid arthritis, with dose titration based on the Disease Activity Score: dose adjustments are common but not always sufficient to assure sustained benefit. Ann Rheum Dis 2004;63:144-8.

2 Haraoui B. Is there a rationale for switching from one anti-tumor necrosis factor agent to another? J Rheumatol 2004;31:1021-2.

3 Favalli EG, Arreghini M, Arnoldi C, Panni B, Marchesoni A, Tosi S, et al. Antitumor necrosis factor alpha switching in rheumatoid arthritis and juvenile chronic arthritis. Arthritis Rheum 2004;51:301-2.

4 Stern R, Wolfe F. Infliximab dose and clinical status: results of 2 studies in 1642 patients with rheumatoid arthritis. J Rheumatol 2004;31:1538-45.

5 Van Vollenhoven RF, Brannemark S, Klareskog L. Dose escalation of infliximab in clinical practice: improvements seen may be explained by a regression-like effect. Ann Rheum Dis 2004;63:426-30.

\section{The T348M mutated form of cryopyrin is associated with defective lipopolysaccharide-induced interleukin 10 production in CINCA syndrome}

\section{T Bihl, E Vassina, M K Boettger, R Goldbach-Mansky, M Seitz, P M Villiger, H U Simon}

$\mathrm{T}$ he term autoinflammatory disease has been proposed to describe a group of disorders characterised by attacks of seemingly unprovoked inflammation without increased levels of autoantibodies or increased numbers of autoreactive $\mathrm{T}$ cells. Such inflammatory conditions are often associated with mutations of genes of the pyrin superfamily. For instance, mutations in cryopyrin (CIAS1, NALP3, PYPAF1) have been found in about $50 \%$ of patients with CINCA syndrome. ${ }^{1}$ These patients are characterised by neonatal onset of cutaneous symptoms, chronic meningitis, and joint manifestations with recurrent fever and inflammation. Despite the description of several mutations within the cryopyrin gene, ${ }^{12}$ it remains unclear how the resulting amino acid changes modify the function of this protein and why inflammation develops under these conditions. A recent study demonstrated increased spontaneous interleukin (IL) l production by macrophages expressing the R260W mutated form of cryopyrin. ${ }^{3}$

\section{METHODS AND RESULTS}

We identified a patient with CINCA syndrome who had a T348M mutation of the cryopyrin gene using genomic DNA extracted from whole blood, as described previously. ${ }^{1}$ Because cryopyrin is largely expressed in monocytes and neutrophils, we performed functional in vitro tests using blood leucocytes of this patient (table 1) at three time points: A. medium inflammatory activity $\left(9.59 \times 10^{9}\right.$ blood neutrophils/1); B. high inflammatory activity $\left(14.950 \times 10^{9} / 1\right)$; and C. low

Table 1 Patient characteristics

41 year old man

Periodic fever and a generalised maculopapular itching erythematous rash since the age of about 8 months

Arthralgia and arthritis with transient swelling beginning in the first year of life

Perceptive deafness beginning after about 30 years

Suffering from abdominal pain and persistent haemorrhagic diarrhoea with increasing age

No increased levels of autoimmune antibodies

Skin histology: cellular infiltrate mainly containing neutrophils

Cranial MRI: internal hydrocephalus and empty sella

Lumbar puncture: sterile chronic meningitis

No growth or mental retardation 

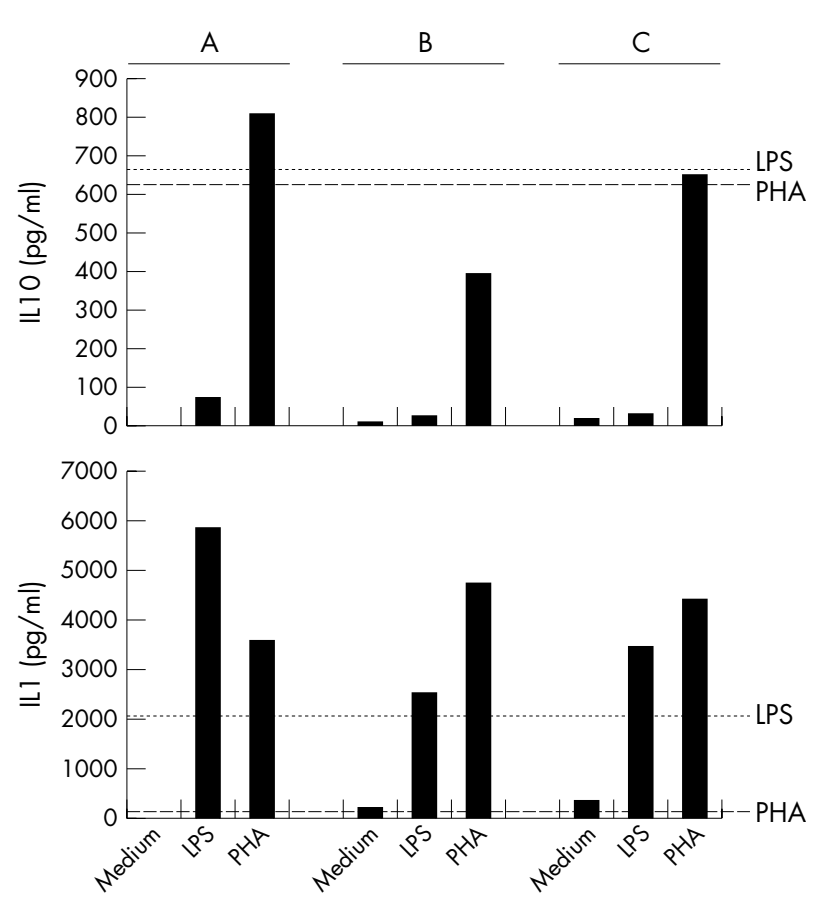

Figure 1 T348M cryopyrin-expressing PBMCs generated ILI but not IL10 upon LPS stimulation. The same cells, however, produced IL10 after PHA stimulation (for culture conditions, see text). The lack of IL10 production after LPS stimulation did not appear to be dependent on the inflammatory condition of the patient (time points A, B, and C, see text). T348M cryopyrin-expressing PBMCs, but not normal PBMCs, generate large amounts of ILI upon PHA stimulation. The horizontal dashed lines represent the mean cytokine levels generated by normal PBMCs after stimulation with LPS and PHA ( $n=4$; means (SEM) were as follows: LPSinduced IL10: 666 (142) pg/ml; PHA-induced IL10: 621 (157) pg/ml; LPS-induced ILI: 2108 (521) pg/ml; PHA-induced ILl: 40 (29) pg/ml).

inflammatory activity $\left(5.47 \times 10^{9} / 1\right)$. The patient did not receive immunosuppressive drug treatment except at time point C (300 mg infliximab).

Earlier work suggested a defect in apoptosis mechanisms associated with mutations of the cryopyrin gene. ${ }^{1}$ We excluded an intrinsic defect of spontaneous neutrophil apoptosis associated with the T348M mutation using methods previously described (data not shown). ${ }^{45}$ We then tested the production of cytokines of peripheral blood mononuclear cells (PBMCs, $1 \times 10^{6} / \mathrm{ml}$ ) after phytohaemagglutinin (PHA, $10 \mu \mathrm{g} / \mathrm{ml}$ ) and lipopolysaccharide (LPS, $10 \mathrm{ng}$ / ml) stimulation (24 hour cultures, 96 well plates, triplicate cultures). ${ }^{6}$ Cytokines were measured in the PBMC culture supernatants using a Cytometric Bead Array Assay (BD Biosciences), according to the manufacturer's instructions. In normal PBMCs both stimuli induced high levels of IL10 (fig 1). In contrast, only PHA but not LPS induced significant levels of IL10 in T348M cryopyrin-expressing PBMC. The defect in LPS-induced IL10 production was not dependent on the inflammatory condition of the patient. Taken together, these data suggest that LPS-mediated but not PHA-mediated IL10 production requires functionally active cryopyrin.

The defect in LPS-induced IL10 production was associated with a particularly high susceptibility to generate ILl after PHA activation (fig 1). Normal PBMCs did not generate significant amounts of ILl in this system. Moreover, and in contrast with R260W macrophages, ${ }^{3}$ T348M PBMCs demonstrated no, or only marginal, ILl production in the absence of stimulation. Thus, it is likely that increased ILl generation particularly occurs after T cell activation, which may result from defective tolerance mechanisms due to decreased IL10 generation upon exposure to microbial antigens, in our patient. Based on these data, we successfully treated our patient with an ILl receptor antagonist (data not shown). Similarly, ILl antagonism proved to be useful in two patients with the R260W cryopyrin variant. ${ }^{7}$

\section{DISCUSSION}

As far as we know, this is the first study providing direct evidence that microbial antigens may trigger an abnormal inflammatory response in an autoinflammatory disease. In contrast, a primary defect of apoptosis, which has been suggested in earlier studies, was, at least in T348M cryopyrinexpressing neutrophils, not seen. Additional investigations should be performed that examine the functional consequences of other known mutations in the genes of the pyrin superfamily. Moreover, further work is required to define the exact hierarchy of signalling events after LPS stimulation to define the place of cryopyrin in this pathway, including its distal molecular targets.

\section{ACKNOWLEDGEMENTS}

We are indebted to the participating patient and to Evelyne Kozlowski (Department of Pharmacology, University of Bern), who provided excellent technical support.

This work was supported by grants from the Swiss National Science Foundation (grant No 310000-107526) and the OPO-Foundation, Zurich, Switzerland.

\section{Authors' affiliations}

T Bihl, M K Boettger, M Seitz, P M Villiger, Department of

Rheumatology/Clinical Immunology/Allergology, Inselspital, University of Bern, Bern, Switzerland

E Vassina, H U Simon, Department of Pharmacology, University of Bern, Bern, Switzerland

R Goldbach-Mansky, National Institute of Arthritis and Musculoskeletal and Skin Diseases, NIH, Bethesda, MD, USA

Correspondence to: Professor H U Simon, Department of Pharmacology, University of Bern, Friedbuehlstrasse 49, CH-3010 Bern, Switzerland; hus@pki.unibe.ch

Accepted 30 January 2005

\section{REFERENCES}

1 Aksentijevich I, Nowak M, Mallah M, Chae JJ, Watford WT, Hofmann SR, et al. De novo CIAS1 mutations, cytokine activation, and evidence for genetic heterogeneity in patients with neonatal-onset multisystem inflammatory disease (NOMID). Arthritis Rheum 2002:46:3340-8.

2 Neven B, Callebaut I, Prieur AM, Feldmann J, Bodemer C, Lepore L, et al. Molecular basis of the spectral expression of CIASI mutations associated with phagocytic cell-mediated autiinflammatory disorders CINCA/NOMID. Blood 2004; 103:2809-15.

3 Agostini L, Martinon F, Burns K, McDermott MF, Hawkins PN, Tschopp J. NALP3 forms an IL-1 $\beta$-processing inflammasome with increased activity in Muckle-Wells autoinflammatory disorder. Immunity 2004;20:319-25.

4 Altznaver F, Conus S, Cavalli A, Folkers G, Simon HU. Calpain-1 regulates Bax and subsequent Smac-dependent caspase-3 activation in neutrophil apoptosis. J Biol Chem 2004;279:5947-57.

5 Altznquer F, Martinelli S, Yousefi S, Thürig C, Schmid I, Conway EM, et al. Inflammation-associated cell cycle-independent block of apoptosis by survivin in terminally differentiated neutrophils. J Exp Med 2004;199:1343-54.

6 Plötz SG, Simon HU, Darsow U, Simon D, Vassina E, Yousefi S, et al. Use of an anti-interleukin-5 antibody in the hypereosinophilic syndrome with eosinophilic dermatitis. N Engl J Med 2003;349:2334-9.

7 Hawkins PN, Lachmann HJ, McDermott MF. Interleukin-1-receptor antagonist in the Muckle-Wells syndrome. N Engl J Med 2003;348:2583-4. 


\title{
Churg-Strauss vasculitis syndrome and leukotriene receptor antagonists
}

\author{
J Ng, R Savage, F McQueen
}

Ann Rheum Dis 2005;64:1382. doi: 10.1136/ard.2004.034272

A 28 year old Middle Eastern woman presented to hospital with shortness of breath and new onset numbness of her foot. Five years previously, in Iraq, she had been diagnosed with severe brittle asthma and sinusitis. After 2 years of management with oral (up to $15 \mathrm{mg}$ prednisone) and inhaled steroid, zafirlukast, a leukotriene receptor antagonist (LRA) was added to her treatment regimen. Despite this, her asthma remained poorly controlled and zafirlukast was stopped after 12 months. Subsequent clinical improvement allowed the prednisone dose to be tapered and then stabilised at $7.5 \mathrm{mg} /$ day. By the time she migrated to New Zealand she had been receiving that dose for 1 year.

At presentation to Auckland City Hospital she was clinically in left ventricular failure with a raised jugular venous pressure. Neurological examination disclosed features of a common peroneal nerve palsy, presumed to be a manifestation of mononeuritis multiplex. Investigations showed a leucocytosis with extreme eosinophilia (white cell count $28.3 \times 10^{9} / 1$, eosinophils $13.3 \times 10^{9} / 1$ ) and erythrocyte sedimentation rate of $40 \mathrm{~mm} / \mathrm{lst} \mathrm{h}$. Renal function and liver function were normal. Troponin $\mathrm{T}$ was raised at $0.64 \mu \mathrm{g} / \mathrm{l}$ (normal $<0.03 \mu \mathrm{g} / \mathrm{l}$ ), indicating myocyte injury. She was antineutrophil cytoplasmic antibody and antinuclear antibody negative. There was moderate left ventricular impairment on echocardiogram, with an ejection fraction of $45 \%$ and a small pericardial effusion. Chest radiography showed cardiomegaly and a fine nodular pattern at the lung bases, which resolved after starting treatment. Attempts to confirm vasculitis on sural nerve and muscle biopsies were unsuccessful.

This patient fulfilled American College of Rheumatology criteria for a diagnosis of Churg-Strauss syndrome (CSS). ${ }^{1}$ As there was evidence of cardiac injury, she scored 1 on the five factors score. ${ }^{2}$

She was treated with prednisone initially at $1 \mathrm{mg} / \mathrm{kg}$ (later tapered to $15 \mathrm{mg} /$ day) and given monthly pulse cyclophosphamide at $0.5 \mathrm{mg} / \mathrm{m}^{2}$, to continue for 12 months according to the protocol proposed by Guillevin and Pagnoux. ${ }^{3}$ She has responded well symptomatically with normalisation of the eosinophil count and erythrocyte sedimentation rate. On echocardiography, the ejection fraction remains unchanged but the pericardial effusion has resolved.

\section{DISCUSSION}

Our patient's experience raises several interesting points. To our knowledge, this is the first case reported in Australasia of CSS occurring in a patient who had received LRA treatment. A possible causal association between the use of zafirlukast and CSS was first suggested in 1998. ${ }^{4}$ The New Zealand Intensive Medicines Monitoring Programme has prospectively monitored adverse events in 1535 patients who received prescriptions for montelukast from 1999 to the present. ${ }^{5}$ Forty three adverse events were considered associated with montelukast, but these did not include CSS or related features. The annual incidence of CSS in patients with asthma has been estimated at 64.4 per million patients. ${ }^{6}$ Thus, any link between montelukast and CSS may not have been detected owing to the small size of the cohort as LRA have not been widely used in New Zealand.

In most reports of CSS occurring in patients receiving LRA, extrapulmonary vasculitic features have developed after steroid reduction. ${ }^{78}$ It has been proposed that this may be because vasculitis has been "unmasked" by reduction of previously suppressive doses of steroid. ${ }^{7}$ This would not apply in our patient as she developed features of CSS after receiving a stable dose of $7.5 \mathrm{mg}$ of prednisone for 12 months.

Other explanations for the association between treatment with an LRA and CSS in this patient include the possibility that zafirlukast has an immunomodulatory role in promoting the development of vasculitis directly (albeit some time later), as has been suggested by Guilpain et al. ${ }^{9}$ Alternatively, the association may have been purely coincidental, and the fact that zafirlukast was stopped 18 months before presentation with CSS makes it harder to implicate the drug in disease pathogenesis in this case.

\section{Authors' affiliations}

J Ng, R Savage, F McQueen, Department of Rheumatology, Auckland District Health Board, Auckland, New Zealand and the Centre for Pharmacovigilance, Dunedin School of Medicine, University of Otago, New Zealand

Correspondence to: $\operatorname{Dr} F$ McQueen, Department of Rheumatology, Building 7, Auckland Hospital, Private Bag 92024, Auckland, New Zealand; f.mcqueen@auckland.ac.nz

Accepted 17 February 2005

\section{REFERENCES}

1 Masi AT, Hunder GG, Lie JT, Michel BA, Bloch DA, Arend WP, et al. The American Rheumatology criteria 1990 for the classification of Churg-Strauss syndrome. Arthritis Rheum 1990;33:1094.

2 Guillevin L, Lhote F, Gayraud M, Cohen P, Jarrouse B, Lortholary O, et al. Prognostic factors in polyarteritis nodosa and Churg-Strauss syndrome: a prospective study in 342 patients. Medicine (Baltimore) 1996;75:17-28.

3 Guillevin L, Pagnoux C. When should immunosuppressants be prescribed to treat systemic vasculitides? Intern Med 2003:42:313-17.

4 Wechsler ME, Garpestad E, Flier SR, Kocher O, Weiland DA, Polito AJ, et al. Pulmonary infiltrates, eosinophilia, and cardiomyopathy following corticosteroid withdrawal in patients with asthma receiving zafirlukast, JAMA 1998:279;455-7.

5 Coulter D. Pro-active safety surveillance. Pharmacoepidemiol Drug Safety. 2000: 9;273-80)

6 Noth I, Strek ME, Leff AR. Churg Strauss syndrome. Seminar. Lancet 2003;361:587-94.

7 Wechsler ME, Finn D, Gunawardena D, Westlake R, Barker A, Haranath SP, et al. Churg Strauss syndrome in patients receiving montelukast as treatment for asthma. Chest 2000;1 17:708-13.

8 Weller PF, Plant M, Taggart V, Trentell A. The relationship of asthma therapy and Churg-Strauss Syndrome: NIH workshop summary report. J Allergy Clin Immunol 2001;108:175-83.

9 Guilpain P, Viallard JF, Lagarde P, Cohen P, Kambouchner M, Pellegrin JL, et al. Churg-Strauss syndrome in two patients receiving montelukast. Rheumatology (Oxford) 2002;41:535-9. 


\title{
A major subset of patients with ankylosing spondylitis followed up in tertiary clinical care require anti-tumour necrosis factor $\alpha$ biological treatments according to the current guidelines
}

\author{
M Temel, P Atagündüz, H Direskeneli
}

Ann Rheum Dis 2005;64:1383-1384. doi: 10.1136/ard.2004.028423

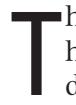
herapeutic options for severe ankylosing spondylitis (AS) have been limited to non-steroidal anti-inflammatory drugs (NSAIDs), corticosteroids, and to some traditional disease modifying drugs (DMARDs) such as sulfasalazine and methotrexate. In view of open label and controlled trials of treatment with a monoclonal chimeric tumour necrosis factor (TNF) $\alpha$ antibody (infliximab), and with recombinant human TNF receptor (etanercept), the need for more effective second line treatments in AS seems to be met. ${ }^{1-4}$

In this study we aimed at determining the proportion of patients with active AS, despite treatment with NSAIDs and second line treatments (sulfasalazine, methotrexate), using current guidelines for anti-TNF treatment in a tertiary clinical care.

\section{METHODS AND RESULTS}

Study patients were selected according to the Modified New York criteria. ASAS and SPARTAN guidelines for biological treatments of AS were used. ${ }^{5}{ }^{6}$ Ninety three patients with AS $(\mathrm{M} / \mathrm{F}=46 / 47$, mean $(\mathrm{SD})$ age 39.5 (11.5) years, mean (SD) disease duration 13.7 (10.5) years) were screened. The University of Marmara Institutional review board approved the study and informed consent was given by the study patients.

Eighty patients (86\%) were receiving NSAIDs: 67/93 (72\%) sulfasalazine and 32/93 (34\%) methotrexate. Disease duration, age, disease activity defined by the Bath AS Disease Activity Index (BASDAI), and drugs used did not differ significantly between male and female patients. Of the 93 patients, 32 (34\%; M/F = 17/15) and 37 patients (40\%; M/ $\mathrm{F}=18 / 19$ ) were defined as having active AS according to SPARTAN and ASAS guidelines, respectively.

Although high mean $\mathrm{C}$ reactive protein (CRP) values are considered critical in defining active AS, the higher mean CRP values detected in the male patients (male $v$ female mean CRP, $259 v 69 \mathrm{mg} / \mathrm{l}, \mathrm{p}=0.054$ ) did not correlate with the ratio of men and women considered to have active AS $($ ASAS $=18 \mathrm{M} / 19 \mathrm{~F}, \quad$ SPARTAN $=17 \mathrm{M} / 15 \mathrm{~F}) . \quad$ Higher $\quad$ CRP values in this group correlated negatively with the use of sulfasalazine $(r=-0.764, \mathrm{p}=0.05)$.

\section{DISCUSSION}

Our study showed that a significant number of patients had active AS (34-40\%) in our patient tertiary care clinic. A recent study reflects the same need for effective treatment in AS, though that study had a higher proportion of patients with active AS (65\%). ${ }^{7}$ In that study, NSAIDs were used as the first line treatment option and use of sulfasalazine and methotrexate was limited. We used combined methotrexate with sulfasalazine for persistent peripheral arthritis, which might have had modifying effects on disease activity in our study group, despite a lack of evidence that conventional DMARDs alter the course of established axial disease, and might explain the differences between the two studies.

According to current diagnostic criteria, patients with AS must have $x$ ray changes for the diagnosis, which take months to years to establish. Two separate studies from Europe emphasise that a substantial period of active disease was already present before the diagnosis. ${ }^{8}{ }^{9}$ As we now know, treatment with biological agents improves the signs and symptoms of axial disease in AS where traditional DMARDs fail. ${ }^{1-4}$ Starting DMARDs at an earlier stage of AS after the diagnosis might provide a chance to assess the effect of conventional treatment in patients with shorter disease duration and enable use of anti-TNF treatment for patients with refractory disease before the radiographic signs of established disease occur.

In a similar study of rheumatoid arthritis ${ }^{10}$ the eligibility of patients receiving routine care to receive treatment with $\mathrm{TNF} \alpha$ agents, according to the inclusion criteria of the studies for biological agents, was also low (prevalence of $8 \%$ ). However, current criteria for defining patients with active AS eligible for anti-TNF treatment, and patient selection criteria of major clinical trials with biological agents, do parallel each other, suggesting that current guidelines for selecting patients with active AS are suitable for routine clinical care.

In conclusion, a significant subset of the patients with AS followed up in our tertiary care clinic require more effective treatment according to current guidelines despite intensive conventional second line treatment.

\section{Authors' affiliations \\ M Temel, P Atagündüz, H Direskeneli, Department of Rheumatology, Marmara University Medical Faculty, Istanbul, Turkey}

Correspondence to: Dr H Direskeneli, Division of Rheumatology, Marmara Medical School Hospital, Tophanelioglu Cad. 13/15, 81190 , Altunizade, Istanbul, Turkey; direskeneli@superonline.com

Accepted 30 January 2005

\section{REFERENCES}

1 Braun J, Brandt J, Listing J, Zink A, Alten R, Burmester G, et al. Long-term efficacy and safety of infliximab in the treatment of ankylosing spondylitis: an open, observational, extension study of a three-month, randomized, placebocontrolled trial. Arthritis Rheum 2003;48:2224-33.

2 Braun J, Brandt J, Listing J, Zink A, Alten R, Golder W, et al. Treatment of active ankylosing spondylitis with infliximab: a randomized controlled multicenter trial. Lancet 2002;359:1187-93.

3 Van der Heijde D, Dijkmans B, Geusens P, Sieper J, DeWoody K, Williamson P, et al. Ankylosing Spondylitis Study for the Evaluation of Recombinant Infliximab Therapy Study Group. Efficacy and safety of a Infliximab in patients with ankylosing spondylitis: results of randomized, placebo controlled trial (ASSERT). Arthritis Rheum 2005;52:582-91.

4 Davis JC, van der Heijde D, Braun J, Dougados M, Cush J, Clegg DO, et al. Recombinant human tumor necrosis factor receptor (etanercept) for treating ankylosing spondylitis. Arthritis Rheum 2003;48:3230-6. 
5 Braun J, Pham T, Sieper J, Davis J, van der Linden S, Dougados M, et al. ASAS consensus statement for the use of anti -tumor necrosis factor agents in patients with ankylosing spondylitis. Ann Rheum Dis 2003;62:817-24.

6 http://www.spondylitis.org/physician_resources/guidelines.aspx, accessed 3 July 2005.

7 Barkham N, Kong KO, Fraser A, Tennant A, Emery P. The unmet need for effective therapy in ankylosing spondylitis. Arthritis Rheum. 2003;48: S175, abstr 360, (suppl).
8 Zink A, Listing J, Klindworth C, Zeidler H. German Collaborative Arthritis Centres. The national database of the German Collaborative Arthritis Centres: Structure, aims, and patients, Ann Rheum Dis 2001;60:199-206.

9 Boonen A, van der Heijde D, Landewe R, Spoorenberg A, Schouten H, Rutten-van Molken $M$, et al. Work status and productivity costs due to ankylosing spondylitis: comparison of three European countries. Ann Rheum Dis 2002;61:429-37.

10 Sokka T, Pincus T. Eligibility of patients in routine care for major clinical trials of anti-tumor necrosis factor- $\alpha$ agents in rheumatoid arthritis. Arthritis Rheum 2003;48:313-18.

\title{
Colchicine responsive periodic fever syndrome associated with pyrin $1591 \mathrm{~T}$
}

\author{
B A C Fisher, H J Lachmann, D Rowczenio, H J B Goodman, S Bhalara, P N Hawkins
}

Ann Rheum Dis 2005;64:1384-1385. doi: 10.1136/ard.2004.030379

$\mathrm{F}$ amilial Mediterranean fever (FMF) is a recessively inherited disorder characterised by recurrent attacks of fever and serositis that usually begin in childhood, last for fewer than 3 days, and which can largely be prevented by colchicine prophylaxis. Identification of the gene associated with FMF, $M E F V$, has facilitated genotype:phenotype studies, and we report here on a patient with a little described exon 9 mutation associated with an atypical inflammatory syndrome.

\section{CASE REPORT}

A 56 year old white French woman presented with normochromic anaemia, haemoglobin $61 \mathrm{~g} / \mathrm{l}$, and recent onset fatigue and headaches. Extensive investigations including upper and lower gastrointestinal endoscopy, autoantibody screens, bone marrow examination, and whole body computed tomography proved normal. There was no family history of note or consanguinity.

Over the following 9 years her symptoms-comprising pyrexia, headache, and drenching night sweats-intensified, occurring about every fourth day and lasting for 24 hours. She required intermittent blood transfusions and her erythrocyte sedimentation rate remained markedly raised. Repeat bone marrow, echocardiogram, radiolabelled white cell scan, and computed tomographic imaging were normal. An investigation for infectious disease was non-diagnostic and a trial of prednisolone ineffective.

The possibility of atypical FMF was considered and was supported by complete resolution of symptoms after the introduction of colchicine $1 \mathrm{mg}$ daily. Before treatment, her median serum amyloid A protein was $338 \mathrm{mg} / \mathrm{l}$ and C reactive protein $56 \mathrm{mg} / \mathrm{l}$. Both markers were in the healthy range of $<10 \mathrm{mg} / \mathrm{l}$ with colchicine (fig 1 ).

Sequencing of $M E F V$ showed a single exon 9 mutation, encoding pyrin I591T; no mutations were found in exons 2, 3, 5, or 10. The TNFRSF1A gene, associated with TRAPS (tumour necrosis factor receptor associated periodic fever syndrome) was wild type. A reduction in colchicine to $0.5 \mathrm{mg}$ /day led to recurrence of symptoms and acute phase response, which resolved when the dose was increased. She remains well and has a normal haemoglobin at 12 months' follow up.

\section{DISCUSSION}

FMF is an inherited inflammatory disorder predominantly affecting people of the Mediterranean littoral, but which has been described in many populations. ${ }^{1}$ The gene associated with FMF, $M E F V$, was cloned in 1997 and comprises 10 exons. ${ }^{1}$ Forty eight mutations associated with FMF have been reported, just

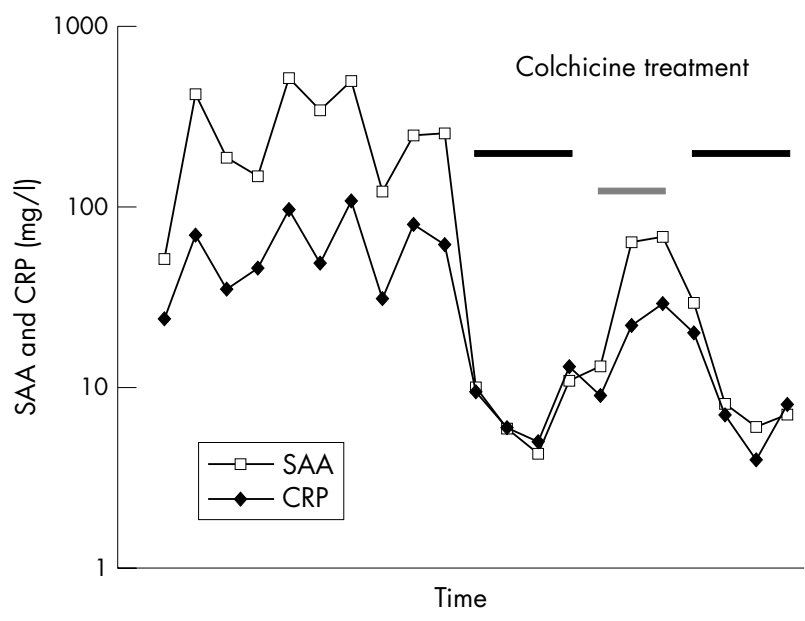

Figure 1 Our patient's acute phase response, plotted on a logarithmic scale, and the effect of colchicine treatment. Her chronic inflammatory activity responded to colchicine $1 \mathrm{mg} /$ day, partially relapsed with $0.5 \mathrm{mg} /$ day, and subsided again when the dose was increased again to $1 \mathrm{mg} /$ day.

five of which are associated with $70-80 \%$ of cases. ${ }^{2}$ Although finding a mutation in each $M E F V$ allele corroborates a diagnosis of FMF, the sensitivity and specificity of DNA analysis are hampered by reduced penetrance, and by the fact that only a single mutation can be identified in up to $20 \%$ of patients with classical FMF. ${ }^{3-5}$ This suggests that certain people may be especially susceptible to a single $M E F V$ mutation, or that other as yet unidentified genes can contribute to the pathogenesis of the disease. The diagnosis of FMF therefore remains clinical, and the Tel Hashomer criteria are well validated for this purpose. ${ }^{67}$

Pyrin I591T was first reported in 2001 with no accompanying clinical data. ${ }^{8}$ A Spanish kindred was subsequently described, in which three siblings were compound heterozygotes for pyrin I591T and M694I, the latter a recognised variant causing FMF. ${ }^{9}$ Only one subject was symptomatic, and the contribution from I59lT was therefore unclear. However, a pathogenic role for pyrin I591T in our patient is supported because she fulfilled diagnostic criteria for probable FMF, had attacks of characteristically short duration which responded to colchicine, and we only identified this mutation in one other case among our large referral practice, in a patient with classical FMF who had a second $M E F V$ mutation, M694V. Furthermore, the absence of serositis and a late onset of symptoms have all been described in FMF. ${ }^{10}$ 
This case illustrates the usefulness of a therapeutic trial of colchicine monitored objectively by frequent acute phase protein measurements in patients with undiagnosed periodic fever syndromes. It also raises the possibility that a low threshold for analysing the FMF gene might disclose a wider spectrum of associated disease.

\section{Authors' affiliations}

B A C Fisher, S Bhalara, Department of Rheumatology, Watford General Hospital, Vicarage Road, Watford, Herts WD18 OHB, UK

H J Lachmann, D Rowczenio, H J B Goodman, P N Hawkins, National Amyloidosis Centre, Department of Medicine, Royal Free and University College Medical School, Rowland Hill Street, London NW3 2PF, UK

Correspondence to: Dr B Fisher, Department of Rheumatology, Charing Cross Hospital, Fulham Palace Road, London W6 8RF, UK; bacfisher@yahoo.com

Accepted 30 January 2005

\section{REFERENCES}

1 Drenth JPH, Van der Meer JWM. Hereditary periodic fever. N Engl J Med 2001;345:1748-57.
2 Shinar Y, Livneh A, Langevitz P, Zaks N, Aksentijevich I, Koziol DE, et al. Genotype-phenotype assessment of common genotypes among patients with familial Mediterranean fever. J Rheumatol 2000;27:1703-7.

3 Paut K, Dubuc M, Sportouch J, Minodier P, Garnier JM, Touitou I. Phenotypegenotype correlation in 91 patients with familial Mediterranean fever reveals a high frequency of cutaneomucous features. Rheumatology (Oxford) 2000;39:1275-9.

4 Aksentijevich I, Torosyan Y, Samuels J, Centola M, Pras E, Chae JJ, et al. Mutation and haplotype studies in of familial Mediterranean fever reveal new ancestral relationships and evidence for high carrier frequency with reduced penetrance in the Ashkenazi Jewish population. Am J Hum Genet 1999;64:949-62.

5 Yilmaz E, Ozen S, Balci B, Duzova A, Topaloglu R, Besbas N, et al. Mutation frequency of familial Mediterranean fever and evidence for a high carrier rate in the Turkish population. Eur J Hum Genet 2001;9:553-5.

6 Livneh A, Langevitz P. Diagnostic and treatment concerns in familial Mediterranen fever. Baillieres Best Pract Res Clin Rheumatol 2000;14:477-98.

7 Grateau G, Pêcheux C, Cazeneuve C, Cattan D, Derichian M, Goossens M, et al. Clinical versus genetic diagnosis of familial Mediterranean fever. Q J Med 2000;93:223-9.

8 Touitou I. The spectrum of familial Mediterranean fever (FMF) mutations. Eur J Hum Genet 2001;9:473-83.

9 Aldea A, Casademont J, Aróstegui J, Rius J, Masó M, Vives J, et al. I591T MEFV mutation in a Spanish kindred: is it a mild mutation or a variant influenced by another modifier? Hum Mutat 2002;20:148-50.

10 Nir-Paz R, Ben-Chetrit E, Pikarsky E, Hassin D, Hasin Y, Chajek-Shaul T. Unusual presentation of familial Mediterranean fever: role of genetic diagnosis. Ann Rheum Dis 2000;59:836-8.

\section{Whale of a tale}

\section{B Rothschild, V Naples}

S pondyloarthropathy is the term applied to a form of arthritis with sentinel alteration of the spine, in the form of syndesmophytes and zygapophyseal joint erosions. ${ }^{1-3}$ Although a single zygapophyseal joint can be damaged by pyogenic or rarely by a granulomatous infection, the only known cause of multiple zygapophyseal joint erosions is spondyloarthropathy, ${ }^{12}$ as previously documented in the sauropod dinosaur Camarasaurus. ${ }^{4}$ Species susceptibility to spondyloarthropathy of the reactive arthritis variety has been clearly documented in non-human primates, identical in character, infectious agent involvement, and response to treatment to that found in humans. ${ }^{5}$

Observation of syndesmophytes and zygapophyseal joint fusion in cetacea (for example, dolphins) ${ }^{6}$ stimulated a systematic survey of cetacean collections for evidence of spondyloarthropathy. That survey exposed a blue whale (Balenoptera musculus) at the American National Museum of Natural History (Washington, DC) (USNM 124326) with erosions of zygapophyseal joints of vertebrae l1-14 (fig l). This specimen, collected in Newfoundland, Canada by $\mathrm{F}$ Leucas, contrasts with another sign of spondyloarthropathy, ${ }^{127}$ sacroiliac joint fusion, present in the mouse-like marsupial Antechinomys laniger (common name, kultarr) at the Center for Biodiversity, Illinois Natural History Survey (Champaign, IL) (UIMMH 39301).

The phylogenetic spectrum of spondyloarthropathy is now extended from the largest mammal (weighing up to $190000 \mathrm{~kg}$ ) that ever lived to one of the smallest, the latter weighing in at less than a twentieth of a kilogram. With apologies to Walt Disney, A whale of a tale and its all true.

\section{ACKNOWLEDGEMENT}

Appreciation is expressed for facilitation of collection access by Charles Potter and Jeff Saunders.

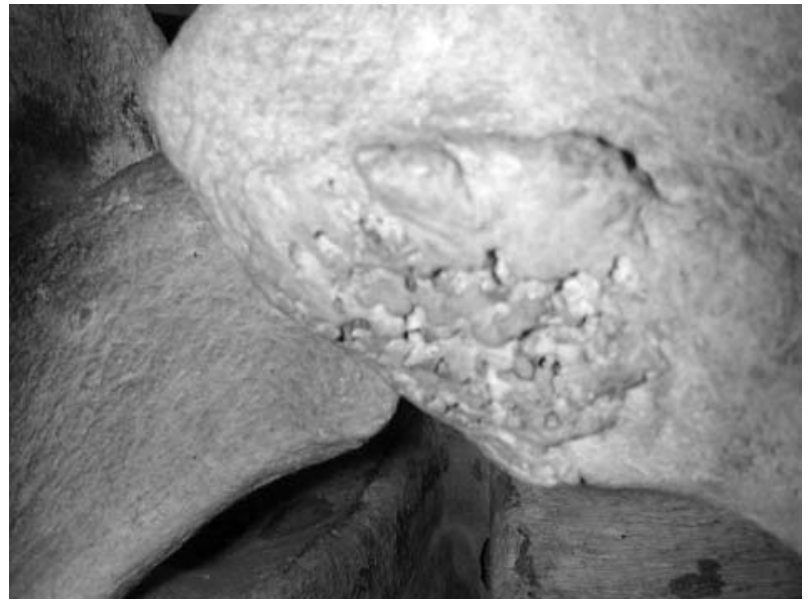

Figure 1 En face view of Balenoptera musculus USNM 124326 13th thoracic vertebra before and after zygapophysis. Photograph taken by VN, a member of the Smithsonian staff, with the assistance of Charles Potter, curator in charge, who provided permission for the study and photography.

\section{Authors' affiliations}

B M Rothschild, Arthritis Center of Northeast Ohio, Youngstown, Ohio 44512, USA; Northeastern Ohio Universities College of Medicine, Rootstown, OH 44527, USA; Carnegie Museum of Natural History, Pittsburgh, PA 15213, USA; University of Kansas Museum of Natural History, Lawrence, KS 66045, USA

V Naples, Division of Vertebrate Zoology, USNM, Smithsonian Institution, Washington, DC 20506, USA; Department of Biological Sciences, Northern Illinois University, DeKalb, Illinois 60115, USA 
Correspondence to: Professor B Rothschild, Arthritis Center of Northeast Ohio, 5500 Market, Youngstown, OH 44512, USA; bmr@neoucom.edu

Accepted 17 February 2005

\section{REFERENCES}

Resnick D. Diagnosis of bone and joint disorders. Philadelphia: Saunders, 2002.

2 Rothschild BM, Martin LD. Paleopathology: disease in the fossil record. London: CRC Press, 1993.
3 San Zhang C, Rothschild BM. Zygapophyseal and costotransvertebral/ costovertebral joints: an anatomic assessment of arthritis impact. Br J Rheumatol 1993;32:1066-71

4 Rothschild BM, Helbling M II, Miles C. Origin of spondyloarthropathy in the Jurassic. Lancet 2002;360:1454.

5 Neiffer DL, Rothschild BM, Marks SK, Urvater JA, Watkins DI. Management of reactive arthritis in a juvenile gorilla (Gorilla gorilla gorilla) with long-term sulfasalazine therapy. J Zoo Wildlife Med 2000;31:539-51.

6 Kompanje EO. Vertebral osteophytosis in cetacea: spondylosis or spondylitis. Z Saugetierkunde 1993;58:316-18.

7 Rothschild BM, Woods RJ. Spondyloarthropathy: erosive arthritis in representative defleshed bones. Amer J Phys Anthropol 1991;85:125-34.

\section{Pagetic hydrocephalus treated with zoledronate}

\section{A Morton}

A case is described of severe untreated polyostotic Paget's disease with severe skull involvement causing hydrocephalus, and its response to treatment with intravenous bisphosphonates is presented.

\section{CASE REPORT}

An 86 year old woman presented with a femoral neck fracture as result of a fall. Her daughter gave a 20 year history of progressive deafness and a 6 month history of confusion, ataxia, and urine incontinence in the setting of untreated Paget's disease. Examination disclosed a profoundly deaf woman with whom communication was only possible by writing, typical bony changes of the skull and both tibiae, but no papilloedema or angioid streaks on fundoscopy. A modified mini-mental state examination was $21 / 30$. Serum alkaline phosphatase (AP) was $1477 \mathrm{U} / \mathrm{l}$ (normal 30-120). Plain radiography showed severe pagetic changes affecting both hemipelves, femora (including the site of fracture), tibiae, and the skull. Computed tomography scanning of the head showed moderate enlargement of both lateral ventricles and the third ventricle, with the fourth ventricle remaining decompressed, consistent with obstructive hydrocephalus (fig 1 ).

The patient declined orthopaedic intervention, magnetic resonance imaging of the brain, or neurosurgical consultation. In view of the neurological involvement her Paget's disease was treated aggressively with three infusions of $90 \mathrm{mg}$ pamidronate given weekly, and her serum AP fell to $650 \mathrm{U} / \mathrm{l} 4$ weeks after presentation. When the effect of this seemed to be plateauing she was then given $4 \mathrm{mg}$ of zoledronate intravenously (fig 2). Her serum AP fell further to $290 \mathrm{U} / \mathrm{l}$ over the next 2 months. Her daughter felt there was improvement in her hearing, but this was not documented objectively with audiometry. Unfortunately, the patient developed sudden respiratory problems and died 4 months after presentation.

\section{DISCUSSION}

Reports of about 20 cases of hydrocephalus complicating Paget's disease have been published. Affected patients presented with ataxia, confusion, urine incontinence, and parkinsonian syndromes, and had relief of their neurological symptoms with ventricular shunting. The use of zoledronate in this case was prompted by the article by Chung and Keen, who reported an excellent response of polyostotic Paget's disease to this drug after variable responses to various bisphosphonates and subsequent resistance to intravenous

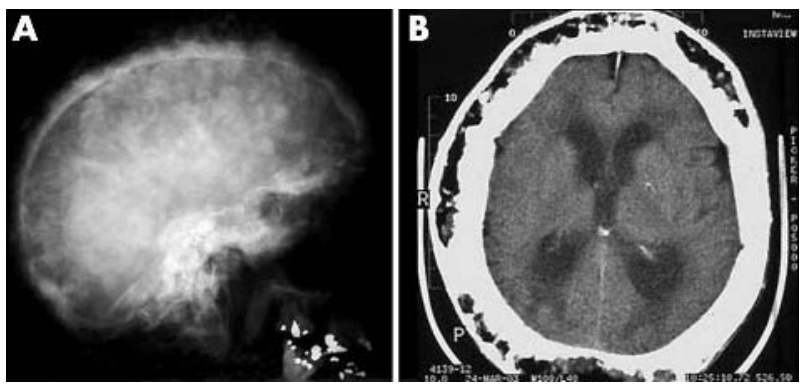

Figure 1 (A) $x$ Ray findings and (B) computed tomography scan of the head.

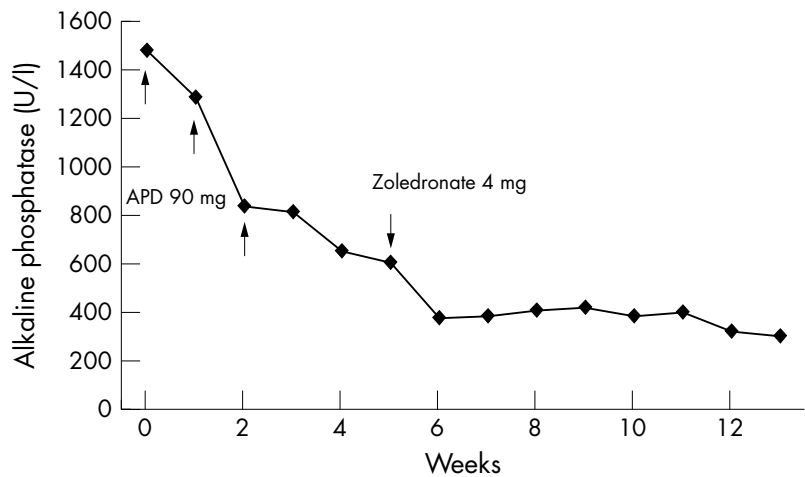

Figure 2 Biochemical response to bisphosphonates. APD, pamidronate.

pamidronate. ${ }^{1}$ Randomised trials are underway comparing response rates between zoledronate and other bisphosphonates.

No competing interest.

Correspondence to: $\operatorname{Dr}$ A Morton, Mater Hospital, Raymond Tce, South Brisbane 4101, Australia; Amorton@mater.org.au

Accepted 7 February 2005

\section{REFERENCE}

1 Chung G, Keen RW. Zoledronate treatment in active Paget's disease. Ann Rheum Dis 2003;62:275-6. 


\section{Oral sildenafil for the treatment of Raynaud's phenomenon and digital ulcers secondary to systemic sclerosis}

\section{J Gore, R Silver}

$\mathrm{R}$ aynaud's phenomenon (RP) with or without digital ulcer formation is a significant cause of morbidity for patients with systemic sclerosis (SSc, scleroderma). Lichtenstein reported oral sildenafil as a treatment of RP for patients with SSc, systemic lupus erythematosus, and idiopathic RP. ${ }^{1}$ His report included 10 patients from his community office practice given sildenafil, $50 \mathrm{mg}$ once orally at bedtime.

\section{METHODS AND RESULTS}

We performed a retrospective chart review of 10 patients with SSc seen at a tertiary care referral centre who were offered sildenafil after standard treatments (calcium channel blockers, $\alpha$ blockers, angiotensin converting enzyme (ACE) inhibitors, aspirin, dipyridamole, pentoxifylline, and/or topical nitrates) had failed. Of the 10 patients, four had limited disease and six had diffuse disease. The mean (SD) age of the patients was 49.9 (9.9) years, and the mean (SD) duration of SSc was 9.5 (6.5) years. The mean (SD) duration of RP was 9.5 (7.5) years. Seven were female and three were male. Eight were white, one was African-American, and one was Hispanic. The starting dose of sildenafil varied among the patients, ranging from $12.5 \mathrm{mg} /$ day to $100 \mathrm{mg} /$ day, in single or divided doses.

Eight of the ten patients treated with sildenafil had a response within a few weeks, with significant reduction in the frequency and severity of RP. Of the eight patients who had digital ulcers refractory to conventional treatment, six experienced complete healing of the ulcers.

One patient, who had recently had a normal coronary arteriogram, did have some chest discomfort after taking the sildenafil. She had taken sildenafil for four months previously without any complaints. Nevertheless, the medicine was discontinued and her chest discomfort resolved. Otherwise, the medicine was well tolerated.

\section{DISCUSSION}

Sildenafil is a phosphodiesterase $\mathrm{V}$ inhibitor that allows accumulation of cyclic guanosine monophosphate (cGMP). cGMP causes a decrease in intracellular calcium, and the result is vascular smooth muscle relaxation and dilatation. ${ }^{2}$ Perhaps in those patients whose digital ulcers failed to heal while they were receiving sildenafil, the failures were the result of fibrosis and/or occlusion of vessels that did not allow further vasodilatation.

The dose prescribed was limited by the availability of the drug. Four patients were allowed only eight tablets a month and so were prescribed $100 \mathrm{mg}$ tablets that were divided into quarters. This allowed the patients to take the medicine daily, albeit in small doses. We present this experience with patients with SSc with RP and digital ulcers in the hopes that further studies will be carried out to examine this new and potentially effective treatment. Clearly, traditional medical and surgical treatments for severe RP and digital ulceration are not adequate for all patients with SSc.

\section{Authors' affiliations}

J Gore, R Silver, Medical University of South Carolina, Division of Rheumatology, Charleston, South Carolina, USA

Correspondence to: Dr J Gore, Medical University of South Carolina, Division of Rheumatology, 96 Jonathon Lucas Street, Suite 912, PO Box 250623, Charleston, SC 29425, USA; gorej@musc.edu

Accepted 30 January 2005

\section{REFERENCES}

1 Lichtenstein JR. Use of sildenafil citrate in Raynaud's phenomenon: Arthritis Rheum 2003;48:282-3.

2 Rybalkin S, Yan C, Bornfeldt K, Beavo J. Cyclic GMP phosphodiesterases and regulation of smooth muscle function. Circ Res 2003;93:280-91. 